\title{
Types of Conflicts in Doctors in Private and Public Sector Hospitals
}

\author{
Shazia Khalid, ${ }^{1}$ Iram Fatima, ${ }^{2}$ Waheeda Khan $^{3}$
}

\begin{abstract}
Objective: The present research was conducted to assess whether doctors of private and public sector hospitals would differ in organizational conflict types after controlling gender.
\end{abstract}

Material and Method: The sample comprised of 178 doctors employed in private and public sector hospitals among which 84 were from private hospitals and 94 were from public sector hospitals. Rahim Organizational Conflict Inventory - III was used to assess the types of conflicts.

Results: Results revealed that the doctors from private sector hospital experienced all types of conflicts more than doctors from public sector hospitals, after controlling for the gender. Further substantive conflict was experienced more than other types of conflicts in both settings.

Date of Submission 16-9-2015

Date of Revision Received 17-11-2015

Date of Acceptance for Publication 13-5-2016

Conflict of Interest: None

Funding Source: None

Khalid S. ${ }^{1}$

Institute of Applied Psychology, University of the Punjab

Fatima I. ${ }^{2}$

Institute of Applied Psychology, University of the Punjab

Khan W. ${ }^{3}$

Jamia Millia Islamia, New Delhi, India
Conclusion: Although, type of sector plays a major role in determining level of conflicts in doctors, yet task related conflicts named as substantive conflicts are dominant in both types of settings whether private or public.

Keywords: Conflict types, doctors, private sector hospitals, public sector hospitals.

\section{Introduction}

Whenever people or groups with different point of views have to work together, conflicts arise. ${ }^{1,2}$ Conflicts also arise from differences in interests and goals and may result in ill feelings, and rivalry if not managed properly. ${ }^{3-8}$ Clash among workers or between workers and administration at work place is known as organizational conflict. Particularly, the administrations cater a wide - field in the study of the conflict because in a managerial set up, there is adequate contribution of grading, power, supremacy and combination of individuals which provide vital basis for outbreak of conflict situations.

The present research studied four types of conflicts among doctors in private and public sector, namely, substantive, affective, masquerading and transforming conflicts. Substantive conflict is academic disagreement to the thoughts and is an important stair to solution of problems. This type of conflict was named as issue conflict, ${ }^{10}$ cognitive conflict ${ }^{11-13}$ and task conflict. ${ }^{14,15}$ Affective conflict arises when there are emotional issues in the group and when people find faults with each other's' behaviors and expressed emotions. ${ }^{6}$ This type of conflict has been well - known as emotional conflict, ${ }^{16}$ psychological conflict ${ }^{17}$ and relationship conflict. ${ }^{15}$ The third type of conflict is masquerading conflict that is about the absurdity when asso- 
ciates have expressive clashes with each other. This conflict appears to be task - related superficially but this is truly emotional. Another type of conflict is transforming. In this conflict individuals express task related conflicts as personal conflicts. Thus, originally academic disagreements are hidden behind relational or interpersonal disagreements. Hospital is one of the most significant organization with comparable hierarchy of autonomy like other organizations. Private and public settings mainly differ in terms of their goals, accessibility and ownership. Private hospitals are run by single bodies who mainly aim to benefit those who can afford them while public sector hospitals are run by government and aim to satisfy health related issues of everybody in the country. A study conducted to see the differences in quality of private and public hospitals in low socio economic countries showed that apart from higher cost, private hospitals in these countries are less structured. They require unnecessary testing and treatment, and have more possibilities of complications. ${ }^{18}$ However, Pakistani studies show that people in general are more satisfied with quality of private hospitals than of public hospitals. ${ }^{19}$ Therefore, it is expected that differences in two settings may affect the types of conflicts experienced by employees.

\section{Literature Review}

Although, number of researches have been conducted highlighting the importance of conflicts for performance and group satisfaction, team efficiency and functioning in different organizational settings, ${ }^{20-22}$ there is dearth of literature on comparison of conflicts in private and public sector organizations except for one study conducted in Pakistan which revealed different levels of different types of conflicts in private and public banks. ${ }^{23}$ Some other studies, however, indirectly allude to possible differences in conflicts in two sectors. For example, Ogunjimi, Ajibola, and Akah found that affective conflicts affected the private health workers more than public health ones. ${ }^{24}$ Further it has also been observed that sector plays more vital role in determining preference on values, conflicts and effectiveness in organization than age, gender, working experience of employee. ${ }^{25}$ In another study conflicts arising in public sector have been reported to be more overt while occurring in private sector are rarely labeled. ${ }^{26}$ It has also been depicted in a research that conflicts in private sector arise due to situation than from any public sector issue or administrative rules. ${ }^{27}$ Since men and women have been observed to differ in their expressiveness of emotions, communication patterns and conflict resolution styles ${ }^{28}$ they may be expected to differ in their conflicts. Therefore, current research aimed to see the differences in conflicts of doctors of private and public hospitals controlling for gender.

\section{Hypotheses}

- Doctors of private and public sector hospitals are likely to differ in organizational conflict types after controlling for gender.

- There would be relative manifestation of different types of conflicts in private and public sector hospitals.

\section{Material and Methods}

Sample consisted of 178 doctors from private $(n=84)$ and public sector hospitals $(n=94)$ with 58 men and 26 women from private hospitals and 50 men and 44 women from public hospitals. They were full time employees of the hospitals. Doctors with work experience minimum of two years were included $(\mathrm{M}=5.46$, 5.11; $\mathrm{SD}=5.14,4.23$ ) for private hospital and public hospitals respectively. Cross - sectional research design was used to carry out the research.

In order to assess the four types of conflicts Rahim Organizational Conflict Inventory - III $^{29}$ was used. Seven items assessed affective conflict, seven items were related to substantive conflict, five items gauged transforming conflict and five items measured masquerading conflict. Each item was to be rated on $7-$ point Likert - type assessment scale, giving the score of 7 to' strongly disagree, and 1 to 'strongly agree'. Scale scores were attained by mean score on each subscale items for each individual. Conceivable scores ranged from 1 to 7 with high score meaning more existence of such sub type of conflict. The Cronbach alphas for the subscales in current study were $.81, .84$, .82 , and .75 respectively. The analysis was carried out after data entry through SPSS version 20.0.

\section{Results}

MANCOVA was performed to investigate the differences of conflict types in doctors working in private and public sector hospitals controlling for gender. 
The investigation revealed that there was significant difference between the doctors of private and public sector hospitals on conflict types [Wilk's Lambda $=0.89, \mathrm{~F}(4,172)$ $=5.42, \mathrm{p}<.001]$.

Concerning the conflict types individually, the results depicted significant differences in two types of sectors with all four types of conflicts experienced more in the doctors working in private sector than doctors working in the public sector hospitals.

In order to further investigate relative level of experience of conflict types in private and public sector hospitals separately two repeated measures ANOVAs were conducted. To investigate the differences in conflict types in specifically in private sector hospitals, one way repeated measures ANOVA was performed.

Findings from Table 2 indicate significant differences in conflict types across doctors of private hospitals.

Pair wise comparisons reveal that substantive type of conflict was experienced more than affecting and masquerading while substantive and transforming were at same level in doctors working in private sector hospitals.

To investigate the differences in conflict types in specifically in public sector hospitals, one way repeated measures ANOVA was performed.

Findings from Table 4 indicate significant differences in conflict types in public sector hospital.

Pair wise comparisons reveal that substantive type of conflict was experienced more than affecting and transforming while transforming and masquerading were at same level in doctors working in public sector hospitals.

\section{Discussion}

Overall, it was observed that doctors in private sector hospitals had higher level of all types of conflicts than
Table 1: Comparing Conflict Types in Doctors of Private and Public Sector $(\mathrm{N}=178)$.

\begin{tabular}{|l|c|c|c|c|c|c|}
\hline \multirow{2}{*}{ Variables } & \multicolumn{2}{|c|}{ Private $(\mathrm{n}=84)$} & \multicolumn{2}{|c|}{ Public $(\mathrm{n}=94)$} & \multirow{2}{*}{$\mathrm{F}(1,175)$} & $\mathrm{p}$ \\
\cline { 2 - 5 } & $\mathrm{M}$ & $\mathrm{SD}$ & $\mathrm{M}$ & $\mathrm{SD}$ & & \\
\hline Affecting & 4.00 & 1.15 & 3.35 & 1.16 & 14.63 & $<.001$ \\
\hline Transforming & 4.17 & 1.19 & 3.33 & 1.34 & 20.17 & $<.001$ \\
\hline Substantive & 4.26 & 1.04 & 3.70 & 1.29 & 9.49 & .002 \\
\hline Masquerading & 4.02 & 1.08 & 3.51 & 1.35 & 7.87 & .006 \\
\hline
\end{tabular}

Table 2: Repeated Measure ANOVA Comparing Conflict Types in Doctors of Private Hospitals $(\mathrm{N}=84)$.

\begin{tabular}{|l|c|c|c|c|}
\hline Variables & $\mathrm{M}$ & $\mathrm{SD}$ & $\mathrm{F}(3,249)$ & $\mathrm{p}$ \\
\hline Affecting & 4.00 & 1.15 & & \\
\hline Transforming & 4.17 & 1.19 & 4.16 & .007 \\
\hline Substantive & 4.26 & 1.04 & & \\
\hline Masquerading & 4.02 & 1.08 & & \\
\hline
\end{tabular}

Table 3: Pair - wise Comparisons for Conflict Types in Doctors of Private Sector Hospitals $(\mathrm{N}=84)$.

\begin{tabular}{|l|l|c|c|c|}
\hline Factor 1(I) & \multicolumn{1}{|c|}{ Factor 1(J) } & MD & SE & $\mathrm{p}$ \\
\hline \multirow{3}{*}{ 1. Affecting } & 2. Transforming & -.17 & .09 & .38 \\
& 3. Substantive & -.26 & .09 & .01 \\
& 4. Masquerading & -.02 & .08 & 1.0 \\
\hline \multirow{2}{*}{ 2. Transforming } & 3. Substantive & -.09 & .08 & .84 \\
& 4. Masquerading & .14 & .09 & .53 \\
\hline 3. Substantive & 4. Masquerading & .24 & .09 & .04 \\
\hline
\end{tabular}

Note: MD: Mean Difference, SE: Standard Error

Table 4: Repeated Measure ANOVA Comparing Conflict Types in Doctors of Public Hospitals ( $\mathrm{N}=94)$.

\begin{tabular}{|l|c|c|c|c|}
\hline Variables & $\mathrm{M}$ & $\mathrm{SD}$ & $\mathrm{F}(3,279)$ & $\mathrm{P}$ \\
\hline Affecting & 3.35 & 1.58 & & \\
\hline Transforming & 3.33 & 1.33 & 8.00 & $<.001$ \\
\hline Substantive & 3.70 & 1.30 & & \\
\hline Masquerading & 3.51 & 1.35 & & \\
\hline
\end{tabular}


doctors in public sector hospitals. This finding is in line with the studies which suggest that private and public sector environments are so different from each other that they may effect on the conflicts of employyees working there.

All the types have been found more experienced in private settings than in public settings. It has been observed that conflict are less prevalent in those environments where roles are well defined and structured, while they are higher in rate in multiple boss circumstances, anxious environment, pervasiveness of radical technology and confused roles. ${ }^{30}$ It might be that private hospitals in Pakistan are less structured, have more anxious environment than public hospitals due to the conflicts of high profit goal of owner and genuine need of patients while prescribing unnecessary high cost tests and treatments to the patients. ${ }^{18}$ Reasons for the differences observed in the present study need to be explored in future studies.

Further, substantive conflict was experienced more than all other types in both private and public settings. It seems reasonable to understand that at work place, where people come to perform their assigned tasks, employees are less likely to engage in relational conflict and more likely to engage in task related conflict. In private and public settings doctors perform similar roles so nature of dominant conflict is also similar. Moreover substantive or task related conflicts have been found to be more productive and constructive as they provide a chance to learn, coordinate, participate, collaborate, compromise, debate, help in decisionmaking process and innovations. ${ }^{31-35}$ Therefore, people exhibit more of those conflict which are beneficial rather than those which are destructive in nature. According to Berry, the substantive conflict appears to represent all our vigorously wanted activities like rivalries, academic deliberations and discussions ${ }^{43}$. This is somewhat that stimulates, provokes and motivates. This rejuvenates people at determination and constructs extraordinary concerns.

\section{Conclusion and Implication}

The results of the study reveal that environment of hospital setting that is primarily determined by the sector, plays an important role in conflicts among doctors. Further, substantive conflict that is constructive in nature is experienced more than other types in both settings. More researches need to be done to clarify the reasons for higher level of conflicts in doctors from
Table 5: Pair - wise Comparisons for Conflict Types in Doctors of Public Sector Hospitals ( $=94)$.

\begin{tabular}{|l|l|l|l|l|}
\hline \multicolumn{1}{|c|}{ Factor 1(I) } & \multicolumn{1}{|c|}{ Factor 1 (J) } & MD & SE & P \\
\hline \multirow{4}{*}{ 1. Affecting } & 2. Transforming & .03 & .07 & .99 \\
& 3. Substantive & -.35 & .07 & .00 \\
& 4. Masquerading & -.17 & .08 & .22 \\
\hline \multirow{2}{*}{ 2. Transforming } & 3. Substantive & -.38 & .09 & .00 \\
& 4. Masquerading & -.19 & .10 & .38 \\
\hline 3. Substantive & 4. Masquerading & .19 & .10 & .36 \\
\hline
\end{tabular}

Note: MD: Mean Difference, SE: Standard Error

private hospitals which will further help the organizational psychologists and counsellors to address the relevant issues and help the doctors to resolve the conflicts.

\section{References}

1. Buddhodev Sinha A. Conflict management: making life easier, The IUP Journal of Soft Skills, 2011; 5 (4): 3143.

2. Jehn KA. A qualitative analysis of conflict types and dimensions in organizational groups. Administrative Science Quarterly, 1997; 42: 530-557.

3. Rahim MA. Effects of emotional intelligence on concerns for equality and problem solving. Managerial Auditory Journal, 2003; 18 (2): 150-155.

4. Hener G. Communication and conflict management in local public organizations. Transylvanian Review of Administrative Sciences, 2010; No 30E: 132-141.

5. Katz D, Kahn RL. The social psychology of organizations (2nd ed.). New York, NY: John Wiley and Sons, 1978.

6. Marquis LB, Huston CJ. Managing Conflict, Leadership Roles and Management Function in Nursing. Philadelphia, 2000.

7. Rahim MA, Magner NR, Shapiro DL. Do justice perceptions influence styles of handling conflict with supervisors?: What justice perceptions, precisely. International Journal of Conflict Management, 2000; 11 (1): 931.

8. Petković M. Organizacionoponašanje, Ekonomskifakultet Beograd, Beograd. 2008.

9. Tjosvold D. Making employee involvement work: Cooperative goals and controversy to reduce costs. Human Relations, 1998; 51 (2): 201-214.

10. Hammer W, Organ D. Organizational behavior. An Applied Psychological Approach. Dallas: Business 
Publications, Inc. 1978.

11. Amason A. Distinguishing effects of functional and dysfunctional conflict on strategic decision making: Resolving a paradox for top management teams. Academy of Management Journal, 1996; 39: 123-148.

12. Cosier R, Rose G. Cognitive conflict and goal conflict effects on task performance. Organizational Behavior and Human Performance, 1977; 19: 378-391.

13. Holzworth J. Intervention in a cognitive conflict. Organizational Behavior and Human Performance, 1983; 32 (2): 216-231.

14. Eisenhardt K, Bourgeois J. Politics of strategic decision making in high - velocity environments: Toward a midrange theory. Academy of Management Journal, 1988; 31: 737-770.

15. Jehn KA. A qualitative analysis of conflict types and dimensions in organizational groups. Administrative Science Quarterly, 1997; 42: 530-557.

16. Pelled L, Eisenhardt K, Xin K. Exploring the black box: An analysis of work group diversity, conflict, and performance. Administrative Science Quarterly, 1999; 44: $1-28$.

17. Ross RS, Ross JR. Small groups in organizational settings. Englewood Cliffs, NJ: Prentice Hall, 1989.

18. Basu S, Andrews J, Sandeep Kishore S, Panjabi R, Stuckle D, Jenkins R. comparative performance of private and public healthcare systems in low- and middle income countries: A Systematic Review. PLoS Med. 2012; 9 (6): e1001244.

19. Irfan SM, Ijaz A. Comparison of service quality between private and public hospitals: empirical evidences from Pakistan. Journal of Quality and Technology Management, 2011; 6 (1): 1-22.

20. Friedman RA, Tidd ST, Currall SC, Tsai JC. What goes around comes around: The impact of personal conflict style on work conflict and stress. International Journal of Conflict Management, 2000; 11: 32-55.

21. DeChurch LA, Marks MA. Maximizing the benefits of task conflict: The role of conflict management. International Journal of Conflict Management, 2001; 12 (1): 522.

22. De Dreu CKW, Van Vianen AEM. Managing relationship conflict and the effectiveness of organizational teams. Journal of Organizational Behavior, 2000; 22: 309-
28.

23. Khalid S. Conflict types and conflict management styles in organizational settings. Unpublished thesis. Lahore: University of the Punjab, 2010.

24. Schmidt SM, Kochan TA. Conflict: Toward conceptual clarity. Administrative Science Quarterly, 1972; 17: 359-370.

25. Mechanic D. Sources of power of lower participants in complex organizations', Administrative Science Quarterly, 1962; 7: 349-364.

26. Bartunek JM, Reid RD. The role of conflict in a second order change attempt. Hidden conflict in organizations: Uncovering behind - the - scenes disputes, 1992: 116142.

27. Brewer N, Mitchell P, Weber N. Gender Role, Organizational status, and Conflict Management Styles, International Journal of Conflict Management, 2002; 13 (1): 78-94.

28. Rahim MA. Classifying Conflict. Managing conflict in Organizations, (4 ${ }^{\text {th }}$ Ed.). New Brunswick, New Jersey: Transaction Publishers, 2011.

29. KirchoffN, Adams JR. Conflict management for project managers. Drexel Hill: Project Management Institute, 1982.

30. Korabik K, Baril GL, Watson C. Managers' conflict management style and leadership effectiveness: The moderating effects of gender. Sex Roles, 1993; 29 (56): 405-420.

31. Jehn KA. A multimethod examination of the benefits and detriments of intra-group conflict. Administrative science quarterly, 1995: 256-282.

32. Amazon AC. Distinguishing the Effects of Functional and Dysfunctional Conflict on Strategic Decision Making: Resolving a Paradox for top Management Teams. Academy of Management Journal, 1996; 39: 123-148.

33. Khalid S, Fatima I, Khan W. Conflict types and conflict management style in public and private hospitals, Pakistan Armed Forced Medical Journal, 2016; 66 (1): 122126.

34. Fiol CM. Consensus, diversity, and learning in organizations. Organization Science, 1994; 5 (3): 403-420.

35. Putnam LL. Productive conflict: Negotiation as implicit coordination. International Journal of Conflict Management, 1994; 5 (3): 284-298. 